\title{
O Originalismo na América
}

INTRODUÇÃO; 1. RETROSPECTIVAHISTÓRICA; 2. ORIGINALISMO EM ROBERT BORK; 3. ORIGINALISMO EM ANTONIN SCALIA; 4. ESPÉCIES DE ORIGINALISMO; 4.1. Textualismo; 4.2. Intencionalismo; 5. CRITICA AO ORIGINALISMO; 5.1. O Império da Maioria; 5.2. Concepção do Estado de Direito centrada nos direitos; 5.3. Decisões politicas mascaradas; CONCLUSÃO; OBRAS CONSULTADAS.

\section{INTRODUÇÃO}

"A nossa Constituição é tão simples e prática que é possivel sempre enfrentar necessidades extraordinárias por mudanças na acerituação e na disposição sem a perda da forma essencial. Eis por que nosso sistema constitucional se demonstrou o mecanismo politico mais soberbamente duradouro jamais produzido pelo mundo moderno." Franklin D. Roosevelt

"O Juiz decide sempre dentro de uma situação histórica determinada, participando da consciência social de seu tempo, considerando o direito todo, e não apenas determinado texto normativo. "Eros Roberto Grau

A Constituição dos Estados Unidos da América é, realmente, um documento fascinante. Já soma mais de duzentos anos de história desde a data de sua ratificação pelos estadosfederados, tendo sido emendada apenas vinte sete vezes ${ }^{1} \mathrm{em}$ todo o período de sua vigência.

Ela, historicamente, aparece como sendo a primeira Constituição a fundar um Estado que, em seu nascedouro, recebeu

${ }^{1}$ Emenda XXVII - Compensation of Members of Congress (1992). 
poderes limitados, ou seja, apenas aqueles poderes que lhe haviam sido delegados pelos entes federados ${ }^{2}$.

A longevidade do Texto Supremo Americano é sem dúvida reflexo da tenacidade orgânica da sua sociedade, bem como das fortes estruturas institucionais que the dão suporte até hoje. Serve, portanto, sempre como fonte de inspiração para realidades sociais menos estáveis, tal como a que nos inserimos.

Não obstante a resistência com que enfrenta o passar do tempo, a Constituição Americana não escapa do debate, que também já se prolonga por muitos anos, acerca do modo adequado pelo qual o conteúdo de seus dispositivos deve ser lido e aplicado pelos Tribunais. A discussão envolve, portanto, saber qual o alcance que o Poder Judiciário deve atribuir aos direitos e liberdades textualmente consagrados na Constituição Americana quando da concretização destes nos casos particulares. As posturas dividemse entre aqueles que defendem a necessidade de se buscar o sentido original da norma constitucional - seja através do resgate da intenção dos constituintes, seja pela definição do sentido objetivo dado ao texto à época de sua edição - e aqueles que pregam a possibilidade de o texto da Constituição ser lido de modo mais amplo e aberto pelos integrantes do Judiciário, a fim de adequarIhe aos anseios e necessidades de uma realidade social que evolui diariamente. A primeira corrente, a qual corresponde ao objeto do presente estudo, será aqui denominada de originalista, enquanto, à segunda será atribuído o nome não-originalista. A querela entre originalismo e não-orginalismo, como veremos, se identifica, de forma estreita, com o debate travado entre a doutrina do "judicial

\footnotetext{
2 "The Constitution of the United States is the first instance in all history of the creation of a government possessing only limited powers. The Magna Charta, the Petition of Right, the English Bill of Rights, and all the other previous efforts to restrain government had merely imposed restrictions on the otherwise unlimited power of government. The framers of the Constitution, however, created a new government which would possess only the powers delegated to it." (Charles Rice, The Bill of Rights and the doctrine of Incorporation, in The Bill of Rights. Original Meaning and Current Understanding. HICKOK JUNIOR, Eugene W. (coord.)., University Press of Virginia, 1991.)
} 
restraint" e a do "judicial activism"3. A primeira corrente se sustenta no argumento de que o Judiciário, por ser a última esfera estatal a se pronunciar sobre os conflitos existentes na sociedade e por não estar limitado por nenhuma outra instância de poder, deve sempre se auto-restringir através de uma leitura mais apegada ao texto legal ou a intenção do legislador. Já a segunda posição, considerando que a lei é sempre criada com certo grau de abstração, defende que o Poder Judiciário está legitimado a fazer o seu conteúdo normativo evoluir com o passar dos tempos e se adaptar às novas realidades. Em última análise, poder-se-ia afirmar que o debate travado na realidade americana busca alcançar, de uma forma ou outra, uma justificativa democrática para o exercício legítimo do poder constitucional por parte do Judiciário.

Como fonte de análise, será, primeiramente analisada a visão hermenêutica adotada por Robert H. Bork para, em seguida, confrontá-la com aquela defendida pelo Justice Antonin Scalia. Como contraponto, serão utilizados o excelente estudo realizado por Paul Brest, no qual propõe uma versão moderada do originalismo como solução para os dilemas constitucionais americanos, e, ainda, algumas idéias pertinentes desenvolvidas por Ronald Dworkin.

Deve ser dito, ainda, que, neste trabalho, preferiu-se utilizar - dentre as inúmeras expressões que se apresentaram no material

3 John Hart Ely, em sua clássica obra, Democracy and Distrust, demonstra as relações entre os dois debates, comparando-os, ainda, com o próprio conflito ente positivismo e jusnaturalismo: "... 'activism' and 'self-restraint' are categories that cut across interpretivism and noninterpritivism, vitually at right angles. (...) The interpretivism-noninterpretivism dichotomy stirs a long-standing debate that pervades all of law, that between 'positivism' and 'natural law'. Interpretivism is about the same thing as positivism, and natural law approaches are surely one form of noninterpretivism." (Democracy and Distrust - A Theory of Judicial Review, Harvard University Press, 1980, p. 1) A comparação feita entre o debate originalismo-não-originalismo com o conflito positivismo-jusnaturalismo deve ser vista com certa moderação, pois definitivamente as duas formas clássicas de se apreender a experiência jurídica não se restringem apenas ao modo como o ordenamento deve ser interpretado pelos tribunais. 
pesquisado ${ }^{4}$ - os termos originalismo e não-originalismo, pretendendo-se, através destas expressões, designar a postura do aplicador do direito no sentido de fiar-se ou não ao sentido atribuído ao texto constitucional à época de sua edição.

Por fim, cabe referir que se busca, neste trabalho, primordialmente descrever e expor algumas saliências que entendemos relevantes deste importante debate constitucional sendo travado nos Estados Unidos da América, sem que, com isso, se esteja a abrir mão de visão crítica do assunto.

\section{RETROSPECTIVAHISTÓRICA ${ }^{5}$}

Não é possível apontar um marco histórico no qual o debate acerca da interpretação original da Constituição Americana tenha surgido.

Sabe-se, todavia, que, quando da ratificação da Constituição de 1787, as discussões acerca da técnica hermenêutica que deveria ser utilizada na aplicação de seus

${ }_{4}^{4}$ Concordamos com a critica feita por Ronald Dworkin ao repudiar a distinção feita por alguns autores entre teorias interepretativas e não-interpretativas. Expõe o autor com a clareza que lhe é típica: "Tornou-se comum distinguir as teorias de revisão judicial entre 'interpretativas' e 'não interpretativas'. As teorias interpretativas (de acordo com essa distinção) afirmam que a revisão judicial de decisões legislativas deve basear-se na interpretação da própria Constituição. (...) As teorias não interpretativas, segundo se afirma, supõem, ao contrário, ser válido que o tribunal, pelo menos algumas vezes, confronte decisões legislativas com modelos retirados de alguma fonte que não o texto, como a moralidade popular, teorias de justiça bem fundadas ou alguma concepção de democracia genuína. (...) esse esquema é pobre, pela seguinte razão. Qualquer teoria passível de revisão judicial é interpretativa, no sentido de que tem como objetivo fornecer uma interpretação da Constituição enquanto documento jurídico original e fundador, e também pretende integrar a Constituição à nossa prática constitucional e jurídica como um todo. (...) As teorias geraimente classificadas como 'não interpretativas' ... são claramente interpretativas em qualquer sentido plausível. " (Uma Questão de Princípio, pp. 44/5, Martins Fontes, São Paulo, 2001)

${ }^{5}$ Não se assume aqui a pretensão de ser exaustivo na descrição dos eventos que marcaram a instauração da postura originalista dentro da realidade americana. Busca-se apenas destacar alguns fatos marcantes da prática jurídica estadunidense que, na nossa compreensão, possibilitam identificar os pontos de partida deste debate constitucional. 
enunciados não chegaram a aparecer durante o processo constitucional. Da mesma forma, à época da incorporação das dez emendas constitucionais que formam o Bill of Rights (1791), também não é possivel localizar defensores de um método específico de interpretação que pudesse ser enquadrado no recente discurso dos originalistas. Neste período, a técnica de interpretação que deveria ser empenhada na construção dos enunciados da Constituição recém promulgada não chegou a ser um tópico de profundo debate. Por esta razão, dentro deste quadro histórico, não se pode afirmar de modo categórico que o método de interpretação desejado pelos legisladores constituintes, naqueles dias, teria sido especificamente o que levasse em consideração as intenções por eles próprios assumidas quando da feitura do documento constitucional ${ }^{6}$.

Foi somente a partir das decisões proferidas pela Suprema Corte Americana, principalmente no período em que presidida pelo Chief Justice Marshall, que se começou a questionar acerca da forma como os dispositivos constitucionais deveriam ser lidos.

Poder-se-ia apresentar como evento germinativo desta discussão, o sempre citado Marbury v. Madison (1803). Através desta decisão, restou consagrado o postulado de que a Constituição, sendo a expressão maior da vontade popular, deveria controlar o exercício de poder por parte do Estado. Dessa forma, não só se atribuiu força normativa ao texto da Constituição, mas também veio a the ser afirmada a supremacia sobre todos os demais atos oriundos do Estado, o que impôs a conclusão de que seus enunciados não poderiam ser tomados como meros

6 "Of the numerous hermeneutical options that were available in the framers' days - among them the renunciation of construction altogether - none corresponds to modern notion of intentionalism. Early interpreters usually applied standard techniques of statutory construction to the Constitution. (...) The relationship of modern intentionalism to this early interpretive theory is purely rhetorical. (...) This debate cannot be resolved ... by the claim or assumption that modern intentionalism was original presupposition of American constitutional discourse. Such claim is historically mistaken." (H. Jefferson Powell, The original understanding of Original Intent, in Interpreting the Constitution. The Debate over Original Intent. Boston: Northeastern University Press, 1990, pp. 87/8) 
conselhos morais às esferas de poder. Deste precedente, inúmeras conseqüências foram retiradas, sendo que não seria exagero afirmar que a principal delas esteja no fato de o texto estampado na Constituição ter sido reconhecido como o ponto paradigmático para a averiguação da legitimidade de toda e qualquer manifestação estatal.

Outro precedente da Suprema Corte que merece destaque é McCulloch v. Maryland (1819). Nesta decisão o Juiz Marshall interpretou a Constituição de tal modo que ampliou os poderes do governo federal. Marshall, nesta ocasião, viu a Constituição como um instrumento afirmativo de princípios gerais e não um catálogo de regras definidas e de aplicação especifica. Com isso, pretendeu demonstrar que as técnicas hermenêuticas mais restritivas e semânticas não poderiam se aplicar a este documento de provisões mais amplas. Por isto, o texto da Constituição não poderia receber o mesmo tratamento e mesma aplicação que outros enunciados de lei. Tal conclusão encontra-se expressada no seguinte trecho deste precedente, citado com freqüência:

"Se a Constituição contivesse uma acurada pormenorização de todas as subdivisões que seus grandes poderes podem admitir e de todos os meios pelos quais podem ser executados, participaria da prolixidade de um código legal e mal conseguiria ser abarcada pelo espírito humano. Provavelmente jamais seria compreendida pelo público. Portanto, sua natureza requer se lhe assinalem apenas as grandes linhas, designem apenas os objetos importantes, deduzindose os ingredientes secundários que compõem tais objetos da natureza dos próprios objetos. Que essa idéia foi nutrida pelos criadores da Constituição norte-americana é coisa que não se infere somente da natureza do instrumento, senão da linguagem." ${ }^{7}$

Além de diferenciar a natureza atribuída à Constituição daquela dada ao simples texto de lei, o Juiz Marshall também

\footnotetext{
${ }^{7}$ In Saul K. Pandover, A Constituição Viva dos Estados Unidos, 1987, IBRASA, p. 101
} 
demonstrou interesse em analisar a possibilidade de o texto constitucional evoluir com o passar dos anos, tendo afirmado:

"Essa disposição é feita numa Constituição destinada a durar séculos e, conseqüentemente, a se adaptar às várias crises dos negócios humanos. Prescrever os meios pelos quais o governo deveria, no futuro, executar seus poderes, seria mudar, inteiramente o caráter do instrumento e dar-lhe as propriedades de um código legal. Houvera sido uma tentativa imprudente dispor, por regras imutáveis, exigências que, se previstas, só podem tê-lo sido vagamente, e que se enfrentam com mais facilidade à medida que ocorrem. (...) Admitimos, como devem admitir todos, que os poderes do governo são limitados, e que seus limites não devem ser ultrapassados. Mas cremos que a sã interpretação da Constituição deve permitir à legislatura nacional a escolha, relativamente aos meios pelos quais se levam a efeito os poderes por ela conferidos, que dê aquele corpo a possibilidade de cumprir os altos deveres a ele destinados, da maneira mais benéfica para o povo." ${ }^{\text {}}$

Da leitura do texto acima transcrito, constata-se que Marshall vislumbrou como necessária a adaptação dos enunciados contidos na Constituição aos novos tempos, a fim de atualizar às necessidades atuais os poderes conferidos ao Estado. No entanto, para Marshall não caberia ao Judiciário averiguar se, na execução dos poderes previsto na Constituição, as medidas utilizadas foram ou não adequadas à persecução do fim constitucionalmente consagrado ${ }^{9}$.

\footnotetext{
${ }^{8}$ Op. cit., p. 105.

${ }^{9}$ Bem demonstra a postura de Marshall o seguinte excerto: "Se, na execução dos seus poderes, o Congresso adotasse medidas proibidas pela Constituição, ou se, com o pretexto de executar seus poderes, o Congresso aprovasse leis para a realização de objetos não confiados ao governo, seria penoso dever deste tribunal, em lhe sendo subrnetido um caso que exigisse tal decisão, dizer que essa lei não era a lei do país. Mas quando a lei não é proibida, e se destina realmente a efetuar qualquer dos objetos confiados ao governo querer aqui indagar do grau da sua necessidade seria ultrapassara linha que circunscreve o departamento judicial, e pisar o terreno legislativo. Esse tribunal rejeita todas as pretensões a esse poder." (op. cit., p. 107)
} 
Verifica-se, portanto, que foi em McCulloch v. Maryland que o debate acerca da maneira pela qual a Constituição deveria ser lida e aplicada pelo Poder Judiciário começou a ganhar forma, mesmo que ainda não se tivesse instalado com todo o seu vigor.

Também marca o período de amadurecimento do debate originalista o precedente do Dred Scott Case - Dred Scott vs. Sandford (1857). Nesta ocasião, a Suprema Corte Americana, já sob a presidência do Juiz Taney, julgou caso em que escravo foi levado por seu amo do Estado escravista de Missouri para o território de Wisconsin, local em que a escravidão já era vedada, tendo o escravo Dred, após retornar para Missouri, movido ação pleiteando sua liberdade ao argumento de que havia vivido em Estado livre. Decidiu a Corte, nesta ocasião, que o escravo não poderia mover ação perante tribunais federais, pois não se qualificava como cidadão. A Corte Maior entendeu que à época da promulgação da Constituição Americana, os negros eram considerados pessoas de condição inferior e não eram considerados cidadãos, razão pela qual não haviam sido incluídos nesta referência do texto constitucional. O seguinte excerto do voto do Justice Taney demonstra, claramente, a postura exegética daquele Tribunal no período:

"Ninguém, presumo, suporá que qualquer modificação da opiniäo pública ou dos sentimentos relativamente a essa desventurada raça, nas nações civilizadas da Europa ou neste país, deva induzir esta Corte a dar às palavras da Constituição um sentido mais liberal, a favor deles (os negros) do que se pretendeu tivessem quando esse diploma foi plasmado e adotado. Semelhante argumento seria absolutamente inadmissivel em qualquer tribunal chamado a interpretá-la. Se qualquer das suas disposições for considerada injusta, existe um meio, previsto nela

\footnotetext{
${ }^{10}$ In BODENHEIMER, Edgar. Ciência do Direito (Filosofia e Metodologias Jurídicas). Trad. De Enéas Marzano. Rio de Janeiro, Forense, 1966; Apud GRAU, Eros Roberto. Ensaio e Discurso sobre a Interpretação/Aplicação do Direito. Malheiros, 2002, p. 109.
} 
própria, pelo qual ela pode ser emendada; porém, enquanto permanecer inalterada, há de ser interpretada hoje como era entendida ao tempo da sua adoção. Ela não é a mesma apenas nas palavras, é também a mesma na sua significação, e delega os mesmos poderes ao governo, reservando e assegurando ao cidadão os mesmos direitos e privilégios; e, enquanto continuar a existir soa a sua forma atual, ela falará não só pelas mesmas palavras, mas com o mesmo sentido e propósito com que falou ao sair das mãos daqueles que a modelaram e ser votada e aprovada pelo povo dos Estados Unidos da América. Qualquer outra regra de interpretação tiraria a esta Corte o seu caráter judicial, fazendo dela apenas um reflexo da opinião popular ou da paixão do momento." 10

Verifica-se, assim, que, nesse período histórico, a postura da Suprema Corte veio a sofrer marcante transição para uma compreensão originalista do texto constitucional estadunidense.

No entanto, o discurso da hermenêutica constitucional baseado na intenção daqueles que criaram o documento fundante somente veio a se instalar, de modo firme, na realidade jurídica americana com o estouro de sua Guerra Civil (1861-1865). Com a instauração do conflito civil nos Estados Unidos da América, surgiram, pela primeira vez, posturas bem definidas que se preocuparam especificamente com a intenção daqueles que elaboraram a Constituição. Assim, a partir deste marco histórico, inúmeras variantes do originalismo passaram a dominar o contexto jurídico americano ${ }^{11}$.

11 "By the outbreak of the Civil War, Intentionalism in the modern sense reigned supreme in the rhetoric of constitutional interpretation. In his inaugural adress, Jefferson Davis described tha Confederate constitution as 'the Constitution formed by our fathers,' a document that differed from older instrument's text only 'insofar as it is explanatory of their well-known intent." $(\mathrm{H}$. Jefferson Powell, The original understanding of Original Intent, in Interpreting the Constitution. The Debate over Original Intent. Boston: Northeastern University Press, 1990, p. 87) 
Em data mais recente, merece destaque, no plano doutrinário, a obra de John Hart Ely, Democracy and Distrust ${ }^{12}$, a qual veio a dar um novo toque ao debate do originalismo. Nela, o autor, promovendo distinção entre matéria de substância e matéria de processo passíveis de revisão judicial, defendeu que os juízes não estavam autorizados a adentrar no conteúdo material das decisões substantivas realizadas por aqueles democraticamente investidos de poder para aprovar as leis, mas apenas para revisar a "eqüidade" (retidão) do processo no qual tais leis foram votadas e aprovadas ${ }^{13}$.

Outro fato que se apresenta como marcante nesta evolução histórica deu-se no ano de 1985, quando o então Advogado Geral dos Estados Unidos, Edwin Meese III, em discurso promovido diante da Ordem dos Advogados daquele país, veio novamente a reativar o debate originalista, pregando que o único guia seguro para os julgamentos seria aquele que se baseasse em uma "jurisprudência da intenção original". ${ }^{14}$ Reaceso o debate público, a resposta veio em seguida, através de artigo publicado pelo Justice William J. Brennan para simpósio realizado na Universidade de Georgetown, no qual veio a atacar diretamente a doutrina da intenção original, apontando ela como técnica de interpretação inadequada para qualquer teoria constitucional ${ }^{15}$.

No entanto, o provável o ápice de fervor deste debate público veio a ocorrer no ano de 1987, quando o Presidente

12 ELY, John Hart. Democracy and Distrust - A Theory of Judicial Review, Harvard University Press, 1980.

$\$ 3$ "...the general theory is one that bounds judicial review under the Constitution 's open-ended provisions by insisting that it can appropriately concern itself only with questions of participation, and not with the substantive merits of the political choice under attack. (...) I doubt there are many who would argue that process is of 'higher value' than substance, though some of us would say that substantive decisions are generally to be limited to policing the mechanisms of decision and distribution." (op. cit., p. 181)

${ }^{14}$ Edwin Meese III, Interpreting the Constitution, in Interpreting the Constitution. The Debate over Original Intent. Boston: Northeastern University Press, 1990, pp. $13 / 21$.

${ }_{15}$ RAKOVE, Jack N. Interpreting the Constitution. The Debate over Original Intent. Boston: Northeastern University Press, 1990, pp. 03/10. 
Reagan nomeou o Juiz Robert Bork para ocupar vaga deixada pelo Justice Lewis Powell na Suprema Corte ${ }^{16}$. A nomeação de Bork para a Suprema Corte foi rejeitada pelo Senado Americano, em razão de adotar a postura, na época tomada com exagero e distorção ${ }^{17}$, de que o Juiz deve buscar sempre a intenção original, sob pena de estar atuando como legislador positivo, sem qualquer base democrática.

Atualmente, vemos que, dentro da Suprema Corte Americana, a corrente originalista encontra enfático suporte nas decisões do Justice Antonin Scalia, que critica de forma bastante ácida as decisões passadas da Corte, nas quais, segundo ele, o texto da Constituição foi lido de modo exageradamente aberto.

Os fatos acima narrados não pretendem formar, de modo algum, um retrospecto exaustivo acerca da evolução do debate. Servem, tão-somente, para demonstrar a longevidade da discussão, bem como a oscilação entre as correntes que prevaleceram na prática jurídica americana durante o transcurso da história.

Feito este pequeno panorama histórico, vejamos os argumentos principais de dois autores que pregam explicitamente a necessidade de se encontrar o sentido original do documento que corporifica a Constituição Americana.

${ }^{16}$ TRIBE, Laurence H.; DORF, Micheal. On Reading the Constitution. Cambridge: Harvard University Press, 1991, p. 03.

${ }^{17}$ Bork foi severamente criticado por defender que a decisão proferida em Shelley v. Kraemer, na qual a Suprema Corte havia anulado contratos que continham restrições raciais, estava equivocada, pois a Constituição Americana não previa tal impedimento nas relações contratuais. Bork repudiou, naquela ocasião, a possibilidade da Suprema Corte adotar posturas políticas em suas decisões, não pretendendo questionar a questão substantiva do litígio. De qualquer modo, tal manifestação veio a the prejudicar quando da sua nomeação à Suprema Corte. 


\section{ORIGINALISMO EM ROBERT BORK}

Ex-professor da Universidade de Yale e Juiz da Corte de Apelação do Distrito de Columbia, Robert $\mathrm{H}$. Bork é bastante conhecido pelo fato de ter sido nomeado pelo Presidente Ronaldo Reagan, em 1987, a uma vaga na Suprema Corte Americana, tendo - Senado Federal negado consentimento a sua nomeação pelo fato de defender que a única técnica de interpretação da Constituição admissível seria a busca pela intenção original dos Constituintes.

O seu pensamento encontra-se bem exposto nos textos "The Original Understanding" e "Neutral Principles and some First Amendment Problems"^9, os quais, aliás, serviram de inspiração para o desenvolvimento do presente estudo.

Bork pretende, através de seus textos, estruturar uma teoria constitucional que permita averiguar até que ponto vai a legitimidade do Poder do Judiciário ao dar aplicação aos enunciados abstratamente estampados no texto da Constituição. Para tanto, inicia seus estudos analisando as premissas contidas no clássico Dilema Madisoniano. O Dilema de Madison questiona a forma pela qual devem ser compatibilizadas e harmonizadas duas posturas que freqüentemente se chocam, quais sejam, a vontade da maioria e a proteção das minorias. A primeira postura é um corolário direto do princípio democrático, através do qual se sustenta que uma decisão política deve sempre ser tomada de acordo com o que determinar a vontade da maioria, pelo simples fato de esta poder ser reconduzida a uma manifestação numericamente majoritária e, portanto, socialmente legitimada. Já na segunda postura, se adota a visão segundo a qual há aspectos da vida nos quais a regra da maioria não pode adentrar, pois há frações da realidade individual que devem ser desenvolvidas com ampla liberdade, sem

${ }^{18}$ In "The Original Understanding, in Contemporary Perspectives on Constitutional Interpretation." Colorado: Westview Press, 1993.

${ }_{19}$ In "Interpreting the Constitution. The Debate over Original Intent." Boston: Northeastern University Press, 1990. 
qualquer interferência das manifestações exteriores, mesmo que estas sejam oriundas da vontade majoritária.

No seio desta relação dicotômica, Bork busca legitimar a autoridade do Judiciário em uma sociedade democrática, mormente considerando que os integrantes deste Poder não são conduzidos aos seus cargos através de um processo representativo da vontade da maioria. Em não sendo democrático o caminho de ingresso dos ocupantes do Judiciário, principalmente dos membros da Suprema Corte, o poder através deles emanado deve, de alguma forma, ser limitado. Esta limitação concretiza-se na necessidade de o Juiz, ao dar aplicação aos dispositivos constitucionais, ater-se a uma leitura mais estreita do seu texto e, portanto, mais apegada ao espírito daqueles que o elaboraram, estes sim com plena legitimação democrática. Ao legislativo atribuise liberdade ampla para realizar as escolhas acerca dos valores fundamentais que deverão imperar na sociedade, pois legitimado pela vontade da maioria, enquanto que ao Judiciário se impõem barreiras, admitindo-.se que o seu poder seja exercitado apenas dentro daquelas linhas previamente traçadas pelos portadores do aval democrático ${ }^{20}$.

Os problemas práticos, porém, começam quando o conteúdo do dispositivo constitucional não pode ser objetivamente extraído de seu texto, não sendo possivel determinar qual o valor fundamental consagrado pelo Legislativo para o caso particular. Para estas situações, Bork defende, enfaticamente, que a única aproximação ao texto constitucional que encontrará legitimidade democrática será aquela que preze pelo sentido original. Afirma o autor, em uma das passagens do seu texto: "In truth, only the approach of original understanding meets the criteria that any theory of constitutional adjudication must meet in order to posses democratic legitimacy." ${ }^{21}$ Para ele, isso significa dizer que o

20 "Where the law stops, the legislator may move on to create more; but where the law stops, the judge must stop." (Contemporary Perspectives on Constitutional Interpretation. Colorado: Westview Press, 1993, p. 57)

${ }^{21}$ Op. cit., p. 50. 
processo hermenêutico deve somente se guiar pelo significado que as palavras possuíam quando o texto constitucional foi promulgado. Não quer dizer com isso que se deva buscar um sentido subjetivo do texto, mas sim aquele que o público em geral atribuía às palavras da Constituição quando da sua edição ${ }^{22}$. Assim, para Bork, somente através desta forma de interpretação constitucional, seriam colocadas as amarras necessárias para que o poder do Judiciário fosse exercitado com legitimação democrática.

A fim de dar aplicação e concretude à técnica de interpretação conforme o sentido original, Bork introduz o conceito de principios neutros. Princípios neutros seriam aqueles preceitos de conteúdo valorativo que a Corte pudesse extrair do texto constitucional e que estivesse disposta a aplicar a todos os casos razoavelmente semelhantes. A neutralidade que se quer dar à aplicação dos princípios extraídos da Constituição exige que estes sejam definidos de forma estrita, permitindo que incidam apenas sobre um número reduzido de $\operatorname{casos}^{23}$. Uma vez definido o conteúdo do princípio neutro, não está a Corte autorizada a escolher em que situações este deverá ser aplicado. Pretende impedir que os tribunais tomem decisões políticas ou imponham valores subjetivos, autorizando-os apenas a descobrir, dentro do texto normativo, princípios que indicarão, para as situações específicas, a forma como os conflitos devem ser solvidos. Assim, com a descoberta do princípio neutro aplicável à questão constitucional em jogo, o Juiz deve transcender os resultados práticos imediatos que seriam atingidos no caso concreto. Demonstraria, com isso, desinteresse e imparcialidade, já que não estaria impondo valores morais próprios, mas sim aqueles antes manifestados pelo Legislador Constituinte.

22 "... what counts is what the public understood. Law is a public act. Secret reservations or intentions count for nothing. All that counts is how the words used in the Constitution would have been understood at the time. The original understanding is thus manifested in the words used and in secondary materials, such as debates at the conventions, public discussion, newspaper articles, dictionaries in use at the time, and the like." (op. cit., p. 51)

23 "Neutral application can be gained by defining a principle so narrowly that it will fit only a few cases." (op. cit. 54) 
Uma das dificuldades que se encontra na tese de Bork surge a partir do modo pelo qual o nível de generalidade dos princípios neutros deve ser definido.

Assim, a teoria constitucional desenvolvida pelo Bork pretende realizar duas tarefas. Primeiramente, encontrar uma base de legitimação democrática para o exercício do poder pelos integrantes do Judiciário, especialmente em razão do fato de não serem eles conduzidos a seus cargos por qualquer via representativa da maioria. Esta legitimação consagra-se quando a aplicação da Constituição é realizada mediante uma leitura atenta ao sentido original do seu texto, ou seja, de acordo com o significado que as palavras contidas na Constituição possuíam à época de sua edição. Em segundo lugar, busca garantir segurança e prospectividade na aplicação da Constituição através da estruturação dos princípios neutros, os quais, ao mesmo tempo, limitam o âmbito de incidência dos valores fundamentais extraídos do texto constitucional através da leitura conforme o sentido original e possibilitam que os destinatários da prestação jurisdicional antevejam a forma como os tribunais decidirão os conflitos. Isso porque a neutralidade do princípio impõe que este seja aplicado a todas as situações que guardem certo grau de similitude.

\section{ORIGINALISMO EM ANTONIN SCALIA}

Antonin Gregory Scalia, nascido em 1936, filho de imigrantes italianos e criado no Queens/NY, sob forte tradição católica, agrega uma legião expressiva de fiéis admiradores, assim como de ferrenhos críticos, em razão da pujança de seus argumentos e, muitas vezes, do conservadorismo de suas posturas $^{24}$. Já tendo acumulado extensa experiência acadêmica e anos de dedicação à magistratura junto ao Tribunal de Apelação

${ }^{24}$ Não é a toa que encontramos, em pesquisa na rede mundial de computadores, sites que se dedicam a elogiar este Juiz da Suprema Corte Americana, bem como a publicar textos agressivos, atacando suas posturas (vide, villainy, Thy Name Is Antonin Scalia, de Robert Scheer, publicado em 12/2000, em robertscheer.com) 
do Distrito de Columbia, foi nomeado pelo Presidente Ronald Reagan para a Suprema Corte no ano de 1986, com a intenção de reverter algumas das doutrinas e políticas liberais introduzidas naquela Corte, enquanto sob presidência dos Chief Justice Warren e Burger ${ }^{25}$. Mesmo não tendo obtido toda a influência esperada pelos seus admiradores, as suas idéias conservadoras indubitavelmente marcaram as decisões oriundas da Alta Corte Americana.

O pensamento de Scalia acerca da interpretação constitucional encontra-se bem exposto em seu artigo "Common-law Courts in a Civil-law System: Role of Unites States Federal Courts in Interpreting the Constitution and Laws"26.

Scalia, em sua obra, mesmo partindo de premissas semelhantes àquelas suscitadas por Bork, dispõe-se a elaborar uma teoria hermenêutica com um enfoque um tanto diferenciado. Para ele, somente teremos uma teoria constitucional adequada, se os juizes estiverem impossibilitados de criar ou modificar o Direito através de suas decisões ${ }^{27}$. A fim de evitar um governo de juizes, propõe-se a criar uma estrutura interpretativa em que eles estejam apegados ao texto escrito da lei. Assim, através de um discurso direto e objetivo, Scalia defende que a norma constitucional apenas pode ser lida de acordo com o que ela efetivamente diz e não o que os legisladores tinham a intenção de dizer, mas não chegaram a incorporar ao seu texto. Funda, com estas premissas, a técnica de interpretação que denomina de textualismo, a qual, segundo nosso autor, é a única forma de se garantir os direitos e liberdades constitucionalmente consagrados e de se preservar a separação no exercício das funções do poder. Isso porque o apego ao texto normativo garante que os destinatários da norma saberão, de antemão, os limites nos quais o Juiz deverá solver o conflito constitucional. A previsibilidade acerca

${ }_{25}$ Christopher E. Smith, Justice Antonin Scalia and the Supreme Court's Conservative Moment. Praeger Pub Text, 1993, p. 03.

${ }^{26}$ In A Matter of Interpretation. Federal Courts and the Law. Princeton: Princeton University Press, 1997. 
do conteúdo das decisões é, na visão do autor, pressuposto necessário para que sejam afastadas as arbitrariedades judiciais.

Em sendo pressuposto de uma interpretação constitucional adequada a necessidade de critérios objetivos e seguros para sua aplicação, Scalia rechaça toda técnica que se baseie na busca pela intenção do legislador, pois crê ser simplesmente impossivel resgatar os sentimentos ou as sensações que o legislador possuía no momento histórico em que um texto legal foi debatido e aprovado. Não temos disponivel qualquer técnica ou instrumento apto a isolar e identificar a intenção subjetiva do legislador ao votar um projeto de lei. Mesmo que conseguíssemos, através de documentação histórica, demonstrar quais teriam sido as inspirações do legislador ao proferir seu voto em determinado sentido, tal não seria suficiente para validarmos uma técnica intencionalista, já que, de acordo com nosso autor, todo e qualquer material histórico encontrado não possui força normativa capaz de dar respaldo jurídico a uma decisão. O texto de lei, e apenas ele, possui a força necessária para revestir de juridicidade as decisões proferidas pelos tribunais. Aliás, a invocação de uma intenção legislativa por parte da Corte é, na maior parte das vezes, utilizada para possibilitar a fuga do texto da lei e a imposição da postura moral daqueles que a integram ${ }^{28}$.

O fato de a doutrina de Scalia não pregar a busca pela intenção ou vontade do legislador - intencionalismo - é o que irá, a princípio, distinguir-the de outros defensores do Originalismo.

Scalia diferencia, ainda, o seu textualismo do construtivismo estrito, bem como de qualquer outra forma de interpretação que se atenha ao plano da literalidade, não aceitando, com isso, a crítica de que sua técnica seja simplória ou engessada. Não nega, porém, que ela seja formalista. Aliás, afirma enfaticamente que ela assim seja. ${ }^{29}$

\footnotetext{
27 "It is simply not compatible with democratic theory that laws mean whatever they ought to mean, and that unelected judges decide what that is." (op. cit., 22) ${ }^{2 B}$ Ver o precedente Church of Holy Trinity v. United States (1892).

29 "Of all the criticisms leveled against textualism, the most mindless is that it is 'formalistic'. The answer to that is, of course it's fomalistic. The rule of law is about form. (...) Long live formalism. It is what makes a government of laws and not of men." (op. cit., 25)
} 
Assim, para ele, a adequada leitura da lei não pode ser nem estrita nem ampla, mas "deve ser interpretada razoavelmente, a fim de conter tudo aquilo que moderadamente puder significar. ${ }^{130}$ Entretanto, o problema central do debate é exatamente definir critérios seguros através dos quais seja possivel encontrar esta interpretação razoável do texto normativo. Infelizmente, na obra estudada, não são fartos os argumentos apresentados no sentido de concretizar a técnica do textualismo, o que dificulta saber como solver os problemas práticos nos casos em que o próprio texto da lei é ambíguo ou lacunoso. Scalia, em apenas um momento de sua obra, aprofunda seu discurso, esclarecendo que a interpretação razoável deve ser aquela que, ao invés de buscar a intenção subjetiva do legislador, encontre uma intenção objetivada. Esclarece que esta intenção objetivada deve ser entendida como sendo "...the intent that a reasonable person would gather from the text of the law, placed alongside the remainder of the corpus juris. ${ }^{\prime 31}$ No entanto, fica sem resposta no estudo oferecido por Antonin Scalia a forma pela qual deveria ser identificada esta intenção que uma pessoa razoáve/ retiraria do texto legal à época de sua publicação.

Com estas considerações, Scalia entende ter apresentado os traços principais da técnica hermenêutica adequada para um Estado Democrático, diferenciando-a das tendências intencionalistas e daquelas doutrinas que se fiam no histórico legislativo. Esta diferenciação, porém, serve apenas para especificar e qualificar a sua doutrina perante outras propostas desenvolvidas por defensores do originalismo. Isso porque o textualismo de Scalia busca seus verdadeiros opositores naqueles que defendem que o aplicador do direito está autorizado a realizar a atualização do texto constitucional promulgado no passado, a fim de methor the adequar às tendências e necessidades hodiernas. Seu ataque, portanto, direciona-se à escola hermenêutica que prega a existência de uma "Constituição Viva". Por este motivo afirma:

30 Op. cit., p. 23.

${ }^{31}$ Op. cit., p. 17. 
"... the Great Divide with regard to constitutional interpretation is not between Framer's intent and objetive meaning, but rather between original meaning (wether derived from Framer's intent or not) and current meaning. The ascendant school of constitutional interpretation affirms the existence of what is called The Living Constitution, a body of law that (unlike normal statutes) grows and changes from age to age, in order to meet the needs of a changing society. And it is the judges who determine those needs and 'find' that changing law." 32

Sendo, para Scalia, o único critério de interpretação a busca pelo sentido original, mostra-se viciada toda decisão judicial que pretenda se adaptar à nova realidade, visando a um resultado específico no caso concreto. O Juiz simplesmente não possui legitimação democrática para identificar os anseios de uma sociedade que evolui, assim como não está autorizado a concretizar tais ideais através de suas decisões. Esta função pertence exclusivamente ao órgão constituinte, devendo este promulgar as emendas constitucionais necessárias para os desejos modernos dos cidadãos sejam positivados. Não há, no texto constitucional, dispositivo que preveja a possibilidade de sua alteração ad hoc, ainda mais promovida por juízes não eleitos. Não se poderia dizer sequer que assim tenha sido a intenção daqueles que moldaram o documento constitucional, pois é da própria essência de uma Constituição a função de consagrar, aos seus cidadãos, direitos, o que vem a impedir sejam estes livremente manipulados ${ }^{33}$. Além disso, defende Scalia que a doutrina da Constituição Viva, ao contrário do que poderia

32 Op. cit, p. 38.

33 "Neither the text of such a document nor the intent of its framers ... can possibly lead to the conclusion that its only effect is to take the power of changing rights away from the legislature and give it to the courts." (op. cit., 41) 
parecer, não evoluiu para trazer à tona novos direitos dos cidadãos, mas sim para restringir ou abolir direitos antes consagrados ${ }^{34}$.

Por fim, ressalta que a flexibilização da Constituição não possui nenhum princípio capaz de guiar os juízes na sua aplicação. A ausência de um princípio que determine os critérios de aplicação da doutrina evolucionista, leva a um subjetivismo na tomada de decisões e este, por sua vez, acarreta um estado de insegurança e imprevisibilidade, que, para Scalia, são os dois fatores determinantes para a elaboração de uma teoria de exegese constitucional. A sua teoria, segundo ele, ao menos neste critério não falha, pois seu aplicador saberá, em definitivo, o que buscar no texto da Constituição: o seu sentido original.

\section{ESPÉCIES DE ORIGINALISMO}

Conforme já destacado, assumimos por originalismo a interpretação constitucional que apenas admite, como de autoridade vinculante, o texto da Constituição ou a intenção daqueles que elaboraram o documento normativo. Esta postura

34 Elaborando esta idéia, Scalia cita o precedente Maryland v. Craig (1990). Tratava-se de um caso levado perante a Suprema Corte envolvendo o crime de abuso sexual de uma criança. A Emenda VI da Constituição Americana, consagrando direitos do acusado em processo criminal, dispõe que "In all criminal prossecutions, the accused shall enjoy the right ... to confront the witnesses against him". Ocorre que, no caso específico, o Tribunal entendeu que o direito de o réu acarear o seu acusador deveria ser excepcionalizado em razão do forte impacto emocional que poderia vir a seu infligido no impúbere. Assim, a criança pode prestar seu depoimento apenas diante do promotor, do defensor e do Juiz, tendo o júri assistido o ato em sistema fechado de televisão. O Justice Scalia restou vencido, pois entendeu que o direito constitucional do acusado garante um confronto cara-a-cara, exatamente para de impor pressão sob aquele que irá testemunhar e evitar, com Isso, acusações levianas. Para ele, um direito constitucional indubitavelmente foi eliminado no caso Maryland v. Craig, pois, em 1791, as crianças já sofriam abusos sexuais e também era mais facilmente abaladas em suas emoções, mas tais fatores não haviam sido motivo, naquela época, para restringir os direitos do acusado. Comentando a decisão da Corte, nosso autor faz o impactante comentário: "I have no doubt that the society is, as a whole, happy and pleased with what my Court decided. But we should not pretend that the decision did not eliminate a liberty that previosly existed." (op. cit., 44). 
exegética defende o apego ao texto ou a busca pela intenção do Constituinte, pois apenas estes limitam a discricionariedade na tomada de decisão e garantem que a Constituição vai ser lida de forma constante durante o passar dos anos.

Assim, pode-se dizer que o originalismo, enquanto um gênero de técnica hermenêutica, vem a ser dividido em duas espécies, quais sejam: o textualismo e o intencionalismo ${ }^{35}$. A primeira defende que o único critério seguro de interpretação é obtido através de uma leitura semântica do texto constitucional. Já a segunda, considerando que a Constituição é um retrato da vontade soberana do povo, entende que é somente através do resgate da intenção dos próprios elaboradores deste documento legal específico que poderemos realizar a adequada interpretação do seu texto. Entre estas duas variedades técnicas, podemos ainda encontrar posturas que vão do moderado ao radical, encontrandose no ponto extremado da postura originalista, de um lado, o literalismo e, do outro, o intencionalismo estrito. Ambas pregam que o único critério capaz de dar juridicidade e legitimidade a uma decisão é, conforme a postura extremada que se siga, o estudo semântico do texto normativo ou a identificação da intenção concreta dos legisladores. As correntes moderadas do originalismo assumem estes mesmos critérios como de extrema relevância para a definição do conteúdo da norma, mas não chegam a afirmar que estes sejam exclusivos e definitivos ${ }^{36}$.

\subsection{Textualismo}

Conforme já apontado, o textualismo se atém ao sentido das palavras utilizadas pelo legislador ao confeccionar o texto normativo para definir o conteúdo da norma. Assim, um textualista, ao se empenhar no trabalho exegético, irá analisar a estrutura

${ }^{35}$ BREST, Paul. The Misconceived Quest for the Original Understanding. In Interpreting the Constitution. The Debate over Original Intent. RAKOVE, Jack N. (edit.), Boston: Northeastern University Press, 1990, p. 227/8.

${ }^{36}$ Op. Cit., p. 227. 
semântica do texto legal, a lexicogenia dos termos aplicados, a localização e a relação entre as palavras, a forma como as frases do dispositivo foram compostas, bem como o contexto no qual os signos estão localizados. Para ele, este é o primeiro ou exclusivo critério para encontrarmos o direito dentro da lei. Isso porque (a) a própria Constituição é um documento escrito; (b) esta foi a forma hermenêutica desejada pelos Constituintes; ou (c) é o critério mais seguro para entendermos a intenção daqueles que elaboraram o texto ${ }^{37}$.

Considerando que, para um textualista, o significado das palavras indicam o sentido da norma, o contexto em que estas são colocadas assume uma relevância fundamental. Duas espécies de contextos deverão ser analisadas pelo exegeta: o contexto lingüístico e o contexto social. Enquanto que o primeiro se dedica ao estudo do vocabulário e da sintaxe, o segundo se preocupa com o entendimento compartilhado acerca dos objetivos que poderiam razoavelmente ser atribuidos ao dispositivo constitucional analisado $^{38}$. Relativamente a este último contexto, será necessário averiguar o sentido que era dado à Constituição por um cidadão médio ${ }^{39}$ pertencente à sociedade da época em que foi promulgada, a fim de se entender qual era o verdadeiro sentido social que as palavras recebiam naquele período e, a partir daí, extrair o conteúdo da norma.

O fato de o textualista buscar o sentido dado por um homem razoável da época em que o texto constitucional foi aprovado para definir o conteúdo da norma o aproxima consideravelmente da postura adotada por um intencionalista. O textualismo não dá qualquer valor às intenções subjetivas do legislador nem às manifestações por ele emitidas durante o processo legislativo. Mas, ao tentar resgatar o contexto social no qual estava inserido aquele

\footnotetext{
37 Op. Cit., p. 229.

${ }^{38}$ Op. Cit., p. 229.

39 Paul Brest utiliza-se da expressão "normal speaker of English", fazendo referência, ainda, à comparação com o antigo conceito do homem prudente. (op. cit., pp. 229 e 253)
} 
que, no passado, lia a Constituição, o exegeta se vê obrigado a, de uma forma outra, realizar uma pesquisa histórica bastante similar àquela realizada por um intencionalista.

Com isso, verifica-se que o textualismo é alvo das mesmas críticas levantadas por aqueles que o defendem e o diferenciam do intencionalismo, pois para darem aplicação à técnica hermenêutica proposta necessitarão, igualmente, de fundamentos históricos que justifiquem o sentido das palavras entendidas pelo homem médio da época em que estas foram escritas. Dessa forma, pode-se dizer - na exata medida em que repudiado pelo próprio $\mathrm{Scalia}^{40}$ em relação ao intencionalismo - que este argumento histórico não é capaz de legitimar uma decisão judicial, pois nenhum documento que fundamente o sentido atribuído à Constituição pelo "homem razoável" terá uma força normativa capaz de dar juridicidade a tal decisão. Além disso, a vontade de se escorar nestes fundamentos para interpretar o texto constitucional não terá jamais o condão de garantir segurança ou certeza na aplicação do Direito ao caso, aliás este o primeiro motivo invocado por um textualista ao defender sua postura hermenêutica.

\subsection{Intencionalismo}

O intencionalista interpreta um dispositivo legal através da recobrança das intenções da pessoa ou das pessoas que assumiram a função de elaborá-lo. Ele dará valor ao texto e a linguagem utilizada pelo legislador, até porque são grandes indicativos das intenções tidas no momento da elaboração da lei, mas não assumirá estes critérios como decisivos e determinantes. Isso porque o verdadeiro sentido da lei não se encontra sempre claramente desenvolvido no seu texto, podendo, em inúmeras situações, estar implicitamente determinado. Verifica-se que o intencionalista pode utilizar-se de três fontes para resgatar a intenção do legislador, quais sejam: (a) pode ele elencar todas as regras de aplicação que foram pensadas pelo legislador durante $o$

${ }^{40}$ A Matter of Interpretation..., p. $34 / 36$. 
processo legislativo, estabelecendo, com isso, um rol subjetivo de casos nos quais teria pensado na incidência da lei; (b) pode, ainda, analisar a linguagem utilizada, tendo em vista que esta é um indicativo das intenções do legislador; e (c) pode, por fim, determinar quais as conseqüências que queriam fossem evitadas com a edição da lei. ${ }^{41}$

Entretanto, como pretenderemos demonstrar, a busca pela intenção do legislador não encontra outro resultado senão a frustração do intérprete ${ }^{42}$. Três são os motivos que levam a este inevitável resultado.

Primeiramente, não há como se afirmar, mantendo-se os parâmetros da mínima razoabilidade, que o legislador tenha imaginado todas as situações possiveis sobre as quais a lei que elaborou pudesse vir a incidir. Haverá, indubitavelmente, fatos da vida que a sensibilidade do legislador não conseguiu captar e, portanto, não consegui deliberar internamente acerca de como a situação particular deveria ser enfrentada. Assim, nestes casos não imaginados pelo legislador, o intencionalista estará diante de uma intenção indeterminada, que em nada lhe ajudará a recompor o conteúdo da norma aplicáve ${ }^{43}$.

Além disso, ao intencionalista caberá, antes de interpretar e aplicar uma norma ao caso concreto, buscar desvendar qual teria sido a vontade do legislador acerca da forma como as suas provisões

41 BREST, Paul. The Misconceived Quest for the Original Understanding. In Interpreting the Constitution. The Debate over Original Intent. RAKOVE, Jack N. (edit.), Boston: Northeastern University Press, 1990, p. 231.

42 Para demonstrar o tortuoso caminho percorrido pelo Intecionalista, Paul Brest (Op. Cit., p. 231) elabora exemplo prático. Cria um cenário em que o Prefeito, com poderes legiferantes autônomos, edita lei, após ter sido pedestre atropelado por carro na praça da cidade, com o seguinte texto "Nenhum veículo será permitido na praça". A partir deste cenário fictício, tenta resgatar as verdadeiras intenções do Prefeito.

${ }^{43}$ Retornando ao exemplo levantando por Paul Brest, questiona-se como o aplicador da lei elaborada pelo Prefeito decidiria sobre a possibilidade de trafegar no parque carrinhos de bebês ou bicicletas. Ambos são veículos, não há dúvida disso, mas teria o Prefeito a intenção de incluílos ou excluí-los na sua norma. E em relação a possibilidade de um carro ser largado de um helicóptero no meio da praça para fins publicitários. Muito provavelmente o Prefeito não teve imaginação suficiente para conceber tal possibilidade ao redigir a lei, razão pela qual, para esta situação, possui uma intenção indeterminada. O resgate de sua intenção nestes casos, portanto, não indicariam o direito aplicável ao caso. 
deveriam ser interpretadas. Somente assim estará ele aplicando integralmente, com sinceridade, o método hermenêutico que prega. $A$ busca pela intenção interpretativa, portanto, é a tarefa primeira do verdadeiro intencionalista. Ocorre que nada impede que o legislador tenha manifestado explicita ou implicitamente a sua vontade de a lei por ele editada seja entendida não de acordo com sua intenção, mas pelo seu próprio texto ${ }^{44}$ ou de acordo com algum critério valorativo mais amplo. O intencionalista que se mantém fiel às premissas que defende não poderá negar a possibilidade de a busca pela intenção do legislador resultar numa intenção interpretativa que negue o intencionalismo como técnica hermenêutica. Isso, por si só, torna parcial e falivel a proposta intencionalista.

Por fim, a maior dificuldade enfrentada por um intencionalista estará em determinar a vontade do órgão legislativo, enquanto composto por uma coletividade de representantes que emitem suas opiniões acerca da lei que estão votando e aprovando ${ }^{45}$. Se há como determinar algo que chamaríamos de intenção coletiva do legislador, esta necessitaria de critérios seguros e objetivos para a sua definição. Não poderíamos aceitar que manifestações particulares de um legislador durante debates travados na fase deliberativa de aprovação da lei tivessem força de determinar a intenção legislativa. O Legislador, individualmente considerado, não é investido de poder legiferante autônomo. Mesmo no caso de atribuirmos a cada Legislador um voto-intenção ${ }^{46}$, no sentido de que a soma das vontades individuais

${ }^{44}$ No exemplo até agora tratado, Brest levanta a possibilidade de o Prefeito dispor normativamente também sobre regras de interpretação. Caso tivesse 0 Prefeito manifestado-se no sentido de que "O intérprete deve atentar-se estritamente a linguagem que utilizel, a despeito das minhas intenções", a tarefa do Intencionalista estaria seriamente prejudicada (Op. Cit., p. 233).

${ }^{45}$ Apelando mais uma vez ao exemplo de Brest, trabalha-se a idéia de que, ao invés de uma norma confeccionada por apenas uma autoridade - o Prefeito -, a mesma lei fosse aprovada por um órgão legislativo composto por cinco membros. Mesmo que a lei tivesse sido aprovada de forma unânime, as intenções de cada um dos membros do legislativo teriam sentido e abrangência distintos. Assim, as dificuldades antes enfrentadas para a determinação da intenção do Prefeito, agora apontariam problemas sem solução (Op. Cit., p. 233).

${ }^{46}$ Op. cit., p. 234. 
que fossem coincidentes entre si pudesse determinar a intenção institucional do órgão legislativo, o problema não estaria solvido. Além da grande dificuldade de um intérprete viabilizar uma tarefa como esta, não podemos obliterar o fato de que todos ou a maior parte dos indivíduos que compõem a coletividade legislativa tenham deixado de imaginar e englobar em suas deliberações uma situação específica, o que acarretaria, também neste caso, uma intenção indeterminada do órgão, frustando, com isso, mais uma vez, a proposta intencionalista.

\section{CRITICA AO ORIGINALISMO}

Tendo antes exposto o pensamento de dois representantes do movimento originalista americano, cabe-nos discorrer sobre os pontos principais levantados por aqueles que criticam esta técnica de hermenêutica constitucional.

\subsection{O Império da Maioria}

Ambos os representantes da escola exegética que antes denominamos de originalismo partem do mesmo argumento a fim de fundamentar a busca pelo sentido original. Dizem que não podemos permitir que juizes não-eleitos venham a criar Direito novo através da interpretação do texto legal ou constitucional, pois, para tanto, teriam que tomar decisões políticas, e estas somente podem ser realizadas por aqueles escolhidos pela sociedade através de um processo representativo da vontade da maioria. Usam, portanto, o que Ronald Dworkin chama de o argumento da democracia ${ }^{47}$.

47 "as decisões políticas, segundo este argumento, devem ser tomadas por funcionários eleitos pela comunidade como um todo, que possam ser substituídos periodicamente da mesma maneira. (...) Os juízes não são eleitos nem reeleitos, e isso é sensato porque as decisões que tomam ao aplicar a legislação tal como se encontra devem ser imunes ao controle popular. Mas decorre daí que não devem tomar decisões independentes no que diz respeito a modificar ou expandir o repertório legal, poís essas decisões somente devem ser tomadas sob o controle popular." (Uma Questão de Princípio, Martins Fontes, 2001, p. 17) 
Isso significa dizer que, em um Estado Democrático, somente estarão legitimadas as decisões de autoridade que puderem ser reconduzidas à manifestação majoritária dos membros da sociedade, pois, assim, presume-se, estará resguardado o interesse de todos. Os juízes ingressam em seus cargos através de processo que não conta com o aval da maioria, razão pela qual, ao aplicarem uma lei, devem assumir o papel de apenas resgatar a vontade ou a intenção daqueles que já haviam legitimamente decido sobre as questões que pudessem gerar conflitos. Fala, ainda, o argumento da democracia que, caso admitíssemos o contrário, ou seja, caso pudessem juízes tomar decisões políticas a fim de solver as situações particulares de modo a inovar o Direito, não poderia a sociedade vir a realizar qualquer modo de controle sobre tais decisões, estando impedida, portanto, de substituir as autoridades que não viessem a exercer de forma satisfatória o seu papel.

A invocação do argumento da democracia pelos originalistas se baseia em três presunções, as quais, como se verá, não se sustentam.

Primeiramente, presumem que a sociedade legitima, conscientemente, apenas as decisões políticas tomadas pelo legislativo, já que este é composto por representantes que ela própria escolheu, ao contrário do que ocorre com a eventual decisão política tomada, no caso particular, pelos integrantes do Judiciário. Entretanto, não podemos dizer que os membros da sociedade realizem distinções entre decisões políticas oriundas do legislativo e aquelas emanadas do Judiciário. Na verdade, uma decisão, independentemente do órgão estatal que a deu origem, encontrará respaldo no seio da sociedade se vier a refletir os interesses e necessidades desta, bem como a respeitar a moralidade nela vigente. Portanto, é a eficácia social da decisão, seja ela oriunda do legislativo, seja do Judiciário, é que Ihe dará a legitimação necessária.

O originalismo assume como verdadeiro, ainda, que todas as decisões acerca do modo como os futuros conflitos deveriam 
ser resolvidos já foram tomadas pelo legislador quando da elaboração do texto da lei. Presumem, assim, que o ordenamento é hermeticamente fechado, já contendo, em si, todas as respostas para a solução dos casos concretos. Ao juiz, portanto, caberia apenas resgatar o sentido destas decisões tomadas no passado, portando-se como a bouche de la loi, ao estilo de Montesquieu. Mostra-se um tanto inverossímil tal assunção, mormente considerando que o legislador simplesmente estaria autorizado a deixar de decidir sobre determinadas situações. O legislador não está incumbido de realizar todas as decisões políticas em determinado momento histórico, sendo infundada qualquer afirmação que assuma que tal tenha ocorrido. Aliás, o próprio fato de não ter usado expressões suficientemente claras e precisas é forte indicativo no sentido de que não teve real intenção de decidir acerca de um assunto específico. Muito ponderado o argumento levantado por Dworkin ao afirmar que: “... eles (os legisladores) podem não ter pretendido criar nenhuma delas, e o fato de que não redigiram sua lei em palavras que levem claramente a efeito alguma das intenções é um argumento muito forte no sentido de que não o pretendiam." ${ }^{448}$

$\mathrm{Na}$ verdade, está o legislador autorizado a deixar que certas opções sejam tomadas pelos representantes das gerações futuras.

Nem através da definição de princípios neutros extraídos do texto normativo, como propõe Bork, poderíamos, com franqueza, afirmar que a solução para todas as situações conflituosas estaria prevista no repertório legal. Com certeza, em uma sociedade que evolui constantemente, surgem situações supervenientes para as quais mesmo estes princípios neutros não seriam suficientes para apresentar uma solução adequada.

Além disso, esta postura, que toma o ordenamento como pronto e acabado, impede receba ele as necessárias atualizações, a fim de que se adapte a novas realidades. Ao deixar de se adequar aos novos anseios da sociedade, o Direito começa gradativamente

${ }^{48}$ Op. cit., p. 20. 
a perder sua aplicação à realidade prática, deixando, com isso, de ser o parâmetro para o direcionamento das condutas. Aliás, é a própria generalidade com que os comandos da lei encontram-se expressos no seu texto que garante a possibilidade de que uma norma, através de sua concretização, seja atualizada e adequada aos novos tempos. Cabe citar a preciosa lição de Gadamer que, ao expor o pensamento de Aristóteles, ensina: "...toda lei se encontra numa tensão necessária com respeito à correção do atuar, porque é geral e não pode conter em si a realidade prática em toda sua concreção. (...) A lei é sempre deficiente, não porque o seja por si mesma, mas porque frente ao ordenamento a que intencionam as leis, a realidade humana é sempre deficiente e não permite uma aplicação simples das mesmas." se dizer que não é possível resgatar a justiça na lei enquanto disposta abstratamente, pois esta somente virá com sua concretização e particularização, momento em que será possível dar-lhe uma interpretação e aplicação eqüitativa.

Por fim, o originalismo toma como certo que a melhor e a mais justa decisão será aquela que refletir a vontade da maioria, pois somente assim o interesse da comunidade como um todo estará resguardado. $O$ argumento que dá suporte a esta postura foi muito bem apresentado por Tocqueville, conforme vemos no seguinte excerto de sua clássica obra:

"O império moral da maioria funda-se em parte sobre a idéia de que há mais conhecimentos e mais sabedoria em muitos homens reunidos do que num só; mais no número de legisladores do que na escolha. (...) O império moral da maioria baseia-se no principio de que os interesses do maior número devem ser preferidos aos do menor."

${ }^{49}$ Hans-Georg Gadamer, Verdade e Método, Vozes, 1999, p. 473/4.

50 Alexis de Tocqueville. A Democracia na América, São Paulo: Editora da Universidade de São Paulo, $3^{a}$ edição, 1987, p. 191. 
Assim, o império da maioria é justificado no fato de que, demonstrando o interesse do maior número de indivíduos, uma decisão terá maior probabilidade de gerar um nível de satisfação mais elevado na sociedade. Tal, por si só, já seria suficiente para garantir a justiça da lei.

Além do seu forte caráter utilitarista (assegura-se a máxima felicidade para o maior número de pessoas), esta proposição não resiste a uma análise mais aprofundada. Conforme havíamos mencionado ao discorrer sobre o Dilema Madisoniano, é certo que há determinados aspectos da vida em sociedade que não podem ser tangidos pelas manifestações oriundas do grupo numericamente majoritário. Isso porque a persecução do bem comum não pode ser obtida através do sacrifício de direitos individuais básicos ${ }^{51}$. Não podemos admitir que a força da maioria venha a utilizar-se desta posição a fim de suprimir direitos naturalmente pertencentes ao indivíduo. Estarão garantidos, da mesma forma, os direitos das facções minoritárias da sociedade ${ }^{52}$. Assim, com o intuito de se evitar a tirania da maioria, nega-se que o argumento da democracia seja suficiente para justificar e fundamentar os direitos dos quais os cidadãos, individualmente considerados, podem dizer-se titulares.

Se é verdade que, em um Estado Democrático, todo poder emane do povo, não podemos extrair como corolário desta afirmação que o poder represente, em todas as situações, a vontade da maioria.

5.2. Concepção do Estado de Direito centrada nos direitos

Conforme afirmado no item anterior, não é possivel fundamentar no argumento democrático a definição dos direitos nos quais o indivíduo está investido. Isso porque, para impedirmos que a vontade da maioria subjugue interesses de minorias, estamos obrigados a admitir que existem direitos que não dependem da manifestação majoritária da sociedade e, portanto, não estarão

${ }^{51}$ RAWLS, John. A Theory of Justice, Harvard University Press, 1999. 
necessariamente consagrados, de forma expressa, no repertório da legislação.

Como, porém, serão estes direitos localizados e impostos na realidade jurídica? De todo material por nós consultado, a proposta que mais tranqüiliza os ânimos em relação a assunto de tamanha polêmica é aquela estruturada por Ronald Dworkin ${ }^{53}$.

Ronald Dworkin afirma que, na concepção de Estado que assume como correta, qual seja, aquela baseada em direitos morais que o cidadão possui frente ao Estado e frente aos demais indivíduos, independentemente de previsão expressa no repertório legal, devemos admitir que os juizes, em determinadas situações, venham a tomar decisões políticas para as resoluções dos conflitos. Ante a insuficiência do argumento da democracia para garantir direitos daqueles que não se encontram em posição majoritária da sociedade, impõe-se reconhecer que aos juízes caberá a tarefa de concretizar estes direitos individuais ou minoritários, mesmo que assim não tivesse sido a vontade do legislador ${ }^{54}$.

Assim, em uma concepção do Estado centrada nos direitos, o Juiz, mesmo que seu cargo não tenha tido respaldo em um processo eletivo, está autorizado a tomar decisões política sim, mas apenas naqueles focos da realidade em que o labor legislativo

52 Sobre a possibilidade de admitirmos o Império da Maioria, cabe-nos citar novamente Tocqueville: "Que vem a ser uma maioria tomada coletivamente senão um indivíduo que tem opiniões $e_{\text {, }}$ mais freqüentemente, interesses contrários a outro indivíduo ao qual chamamos minoria? Ora, se admitirmos que um homem revestido de poder extremo pode abusar dele contra seus adversários, por que não admitiremos também a mesma coisa para uma maioria? Os homens, ao se reunirem, terão mudado o caráter? (...) Para mim, não seria possivel acreditar nisso; e o poder de tudo fazer, que recuso a um só de meus semelhantes, eu não o atribuiria nunca a vários deles." (Op. cit., p. 194)

${ }^{53}$ O texto por nós consultado para captarmos o pensamento do Professor de Oxford foi o brilhante "Os juízes políticos e o Estado de Direito", in Questão de Princípio, pp. 3/39.

54 "... os indivíduos têm poderes na concepção de Estado de Direito centrada nos direitos, que não têm na concepção centrada na legislação. Eles têm o direito de exigir, como indivíduos, um julgamento específico acerca de seus direitos. Se seus direitos forem reconhecidos por um tribunal, esses direitos serão exercidos, a despeito do fato de nenhum Parlamento ter tido tempo ou vontade de impô-los." (op. cit., p. 31) 
não tenha sido suficiente para consagrar determinado direito individual ou que esteja em disputa direitos de frações minoritárias da população.

A fuga da soberania popular se justifica nestas situações, pois a decisão tomada pelo Juiz não poderá estar sujeita às pressões ou aos interesses dos grupos majoritários. Ao Juiz devem ser garantidas a tranqüilidade e a isenção diante da opinião pública para decidir se o indivíduo postulante possui ou não o direito do qual se diz titular, devendo, durante o processo deliberativo da tomada de decisão, analisar os padrões de moralidade vigentes. Isso não que dizer que o juiz estará impondo ideologias e convicções próprias nem que estará fazendo tábula rasa do direito positivado. Estará, na verdade, aplicando a sua visão, imparcialmente, acerca de questões políticas e morais que são relevantes na sociedade, com intuito de extrair destes parâmetros os argumentos necessários para plenamente fundamentar a sua decisão. A decisão tomada pelo Juiz, nos moldes em que descrita, assume relevante caráter político. Isso não que dizer que o texto legal vigente possa ser desprezado. No modelo proposto por Dworkin, a legislação continua a exercer influência. Durante o processo de averiguação dos direitos morais nos quais os indivíduos estão investidos o Juiz deverá elaborar, abstratamente, um princípio que seja compatível com as questões em disputa no caso concreto, bem como com o restante da legislação em vigência. O Direito Positivo, assim, atua como limitador das decisões políticas tomadas pelos juizes, servindo como critério último para controle de sua aplicabilidade. Isso significa dizer que, não obstante se admita que o Juiz realize decisões de cunho político em determinados casos, não poderá ele vir a impor suas convicções acerca da moralidade vigente naquelas questões em que a vontade da maioria, de fato, deve imperar. Refiro-me, aqui, às decisões que se direcionam a estruturar programas (objetivos) políticos, econômicos e sociais de larga escala e, em última análise, se propõem a buscar o bem comum. 
Este processo de tomada de decisão é melhor esclarecido nas palavras do próprio Dworkin:

"Um juiz que segue a concepção do Estado de Direito centrada nos direitos tentará, num caso controverso, estruturar algum princípio que, para ele, capta, no nivel adequado de abstração os direitos morais das partes que são pertinentes às questões levantadas pelo caso. Mas ele não pode aplicar tal princípio a menos que este, como princípio, seja compatível com a legislação, no seguinte sentido: o princípio não deve estar em conflito com os outros princípios que devem ser pressupostos para justificar a regra que está aplicando ou com qualquer parte considerável das outras regras." 55

Esta concepção do Estado de Direito, portanto, garante ao indivíduo, especialmente os situados em frações minoritárias da sociedade, que seus direitos serão impostos, mesmo quando não consagrados expressamente através das manifestações de vontade da maioria. Neste modelo, ao Juiz é dada certa margem de liberdade para dizer dos direitos morais dos indivíduos, não obrigando-o a realizar a frustrante tarefa de resgatar a vontade ou intenção do legislador para legitimar sua decisão.

\subsection{Decisões políticas mascaradas}

O iter decisório descrito e proposto por Ronald Dworkin pode soar para o leitor como um tanto idealizado ou talvez até ficcional. Entretanto, não podemos negar que o Juiz quando se coloca diante de um caso em que o compêndio legislativo não se mostra apto ou suficiente para garantir uma solução que, ao seu entendimento, seja equânime, irá proceder, mesmo que apenas no foro de sua intimidade, junto à sua consciência, do modo antes descrito.

${ }^{55}$ Op. cit., p. 15. 
Ocorre que nos acostumamos a ver este procedimento, quando realizado pelo Juiz, ser encoberto por manobras e estratagemas dotadas de certo grau de embasamento jurídico - tal como se dá quando a interpretação da lei é fundamentada no seu espírito, na intenção do legislador ou no sentido original do seu texto -, a fim de garantir a legitimidade da decisão.

Todas estas técnicas não passam de ficções criadas pelo aplicador do direito com a intenção de dar uma máscara legitimadora a verdadeiras decisões políticas. Elas, de nenhum modo, garantem que a decisão será mais justa ou mais correta.

Em se agindo desta forma, na verdade, impede-se que os reais principios de moralidade política que foram confrontados e compatibilizados pelo Juiz com a legislação vigente, durante a tomada de decisão, sejam efetivamente conhecidos e levado ao debate público. Mais coerente, portanto, é que as decisões políticas, realizadas naquelas situações que antes se mencionou, fossem explícitas, para que os princípios estruturados pelo Juiz pudessem ser confrontados e discutidos por todos participantes do discurso jurídico. Ao se permitir que os verdadeiros motivos utilizados pelos juízes na resolução das questões de política sejam conhecidos, não estaria retirando a legitimidade democrática de sua decisão. Na verdade, tal proceder "...enriquece a democracia ao acrescentar um fórum independente, um fórum do princípio, e isso é importante, não apenas porque a justiça pode ser feita ali, mas porque o fórum confirma que a justiça, no fim, é uma questão de direito individual, não, isoladamente, uma questão do bem público." 56

Assim sendo, retornando ao ponto por onde iniciamos este pequeno estudo, pode-se concluir que a postura adotada pelo originalismo, seja a baseada na intenção do legislador, seja no entendimento original do texto, realiza um desserviço à prática jurídica, pois, obrigando o Juiz a utilizar-se destes fictícios subterfúgios, afasta do amplo debate público as verdadeiras razões que fundaram sua decisão. Vale, portanto, a censura muito bem

${ }^{56}$ Ronald Dworkin, op. cit., p. 38/9. 
colocada por Paul Brest: "It is simply anti-democratic to conceal something as fundamental as the nature of the constitutional decisionmaking ... If the Court can't admit what it is doing, then it shouldn't do it. ${ }^{557}$

\section{CONCLUSÃO}

Pretendeu-se com o presente estudo descrever os principais traços de um debate constitucional que já se prolonga por muitos anos na realidade jurídica dos Estados Unidos da América, qual seja, a necessidade de se adotar, em um Estado Democrático, uma teoria da interpretação que esteja apegada ao sentido original que era atribuído à Constituição na época de sua elaboração, seja pelo apego semântico ao seu texto (Textualismo), seja pela busca da intenção daqueles que elaboraram o documento constitucional (Intencionalismo). O trabalho de pesquisa desenvolvido buscou retratar, através do ensinamento de Robert Bork e de Antonin Scalia, as posturas e os vícios daqueles que se filiam à escola exegética que, no contexto jurídico americano, é denominada de originalismo.

Vimos, em ambos os autores estudados, que a busca pelo sentido original da lei, seja pela intenção do legislador, seja pelo entendimento originário dado ao seu texto, fundamenta-se na necessidade de não permitirmos que os Juízes - pessoas ingressadas em órgãos do Estado através de processo não-eletivo - possam tomar decisões desamparadas do texto legal, o que, segundo esta postura, seria aceitar pacificamente que estivessem eles a aplicar conviç̧ões políticas e morais próprias, as quais não representariam a vontade manifestada através do processo deliberativo da maioria. A discussão travada na prática jurídica americana, portanto, assume, como questão de fundo, a própria legitimação democrática das decisões tomadas por juízes não-

${ }^{57}$ Op. cit., p. 250. 
eleitos nas situações em que estas fossem fundamentadas em argumentos não extraídos do próprio repertório normativo.

Feita tal constatação, tentamos demonstrar a insuficiência do argumento da democracia, segundo o qual os juízes não estão autorizados a tomar decisões políticas para resolver as disputas em que estivesse envolvida a discussão acerca de direitos pertencentes ao indivíduo, pois estas já foram tomadas, integralmente, pelo órgão legislativo, único legitimado a tanto, já que escolhido democraticamente pela sociedade. Como dito antes, a insuficiência do argumento democrático reside, principalmente, no fato de presumir que o repertório legal em vigor é completo e acabado, sendo, assim, absolutamente suficiente para a resolução de todos os conflitos particulares que viessem a surgir. Conseqüência disso é que ao Juiz caberá apenas declarar o sentido das decisões tomadas no passado e o impedirá de constituir qualquer direito novo a fim de adequar suas decisões aos desejos e anseios de uma sociedade que constantemente evolui. Entretanto, o bom senso e a coerência nos impõem ver o ordenamento, não como algo que já nasceu em estado de perfeição, mas como algo complexo e dinâmico que necessita sempre se adequar à realidade. Aliás, é contra-intuitivo imaginarmos um órgão composto por legisladores que se considerassem omniscientes e infalíveis a ponto de se sentirem autorizados a decidir e positivar, em um dado momento histórico, todas as soluções para os conflitos que viessem a ser enfrentados pelas futuras gerações. $O$ ordenamento, portanto, deve ser visto como algo moderadamente aberto, a fim de poder receber as influências daqueles que vivem na atualidade e daqueles que viverão no futuro.

Além disso, apontamos que o processo deliberativodemocrático, que assume como força motora a representação dos interesses majoritários, não garante que serão preservados ou consagrados todos direitos pertencentes ao indivíduo enquanto tal, especialmente os direitos de facções minoritárias da sociedade. Isso não significa, de modo algum, afirmar que a utilização do processo democrático para a tomada das decisões seja algo 
negativo ou indesejável, mas apenas que ele, por si só, é insuficiente para garantir a imposição plena dos direitos inerentes à pessoa do cidadão.

Por esta razão, adotando os ensinamentos de Ronald Dworkin acerca da concepção do Estado de Direito centrada em direitos, impõe-se tomar em consideração que há determinadas esferas da realidade onde a vontade da maioria, a qual, de regra, manifesta-se através dos atos produzidos pelos seus representantes no Legislativo, não poderá imperar. Naqueles focos da vida em que a atividade legislativa não desenvolvida de modo satisfatório para consagrar um direito racionalmente pertencente ao indivíduo ou na qual o processo democrático-representativo veio a desprezar direito de determinada minoria, caberá ao Juiz, mesmo que não avalizado por eleição popular, decidir acerca da existência ou não destes direitos. Não se poderá dizer que a decisão tomada pelo juiz, nos termos em que proposto, tenha assumido um sentido verdadeiramente jurídico, pois esta definitivamente não buscou seu fundamento determinante no ordenamento positivado e vigente. Será, na verdade, uma decisão política, no sentido mais estrito da palavra. O fato de se invocar a intenção do legislador ou o sentido semântico original do texto normativo, não tornam jurídicas as decisões tomadas naquelas situações específicas, mas apenas as revestem com uma falsa legitimação democrática, afastando do debate público os verdadeiros motivos que compuseram as razões de decidir do Juiz. 


\section{OBRAS CONSULTADAS}

BORK, Robert $\mathrm{H}$., The Original Understanding, in Contemporary Perspectives on Constitutional Interpretation. Colorado: Westview Press, 1993.

BRISBIN JR, Richard A., Justice Antonin Scalia and the Conservative Revival. The Johns Hopkins University Press: Baltimore and London, 1998.

DWORKIN, Ronald. BORGES, Luís Carlos (trad.). Uma Questão de Princípio. São Paulo: Martins Fontes, 2001.

. Taking Rights Seriously.

Cambridge: Harvard University Press, 1978.

ELY, John Hart. Democracy and Distrust. A Theory of Judicial Review. Cambridge: Harvard University Press, 1980.

GADAMER, Hans-Georg. Verdade e Método. Editora Vozes, 1999, $3^{\text {a }}$ edição.

GRAU, Eros Roberto. Ensaio e Discurso sobre a Interpretação/Aplicação do Direito. Malheiros, 2002.

HICKOK JÚNIOR, Eugene W. (coord.). The Bill of Rights. Original Meaning and Current Understanding. University Press of Virginia, 1991.

MADISON, James; HAMILTON, Alexander; JAY, John. The Federalist Papers. Penguin Classics, 1987.

PADOVER, Saul K. A Constituição Viva dos Estados Unidos. IBRASA, 1987.

RAKOVE, Jack N. (edit.). Interpreting the Constitution. The Debate over Original Intent. Boston: Northeastern University Press, 1990.

SCALIA, Antonin. A Matter of Interpretation. Federal Courts and the Law. Princeton: Princeton University Press, 1997.

SMITH, Christopher E., Justice Antonin Scalia and the Supreme Court's Conservative Moment. Praeger Pub Text, 1993.

TRIBE, Laurence H.; DORF, Micheal. On Reading the Constitution. Cambridge: Harvard University Press, 1991. 
American Constitucional Law.

$3^{\mathrm{a}}$ d. New York: Foundation Press, 2000.

TOCQUEVILLE, Alexis de. SILVA, Neil Ribeiro da (trad.). A Democracia na América. São Paulo: Editora da Universidade de São Paulo, $3^{a}$ edição, 1987. 